\title{
Towards a Learning System for University Campuses as Living Labs for Sustainability
}

\author{
L.A. Verhoef \\ Delft University of Technology \\ M. Bossert \\ Fachhochschule Stuttgart, Hochschule fur Technik \\ J. Newman \\ Massachusetts Institute of Technology
}

See next page for additional authors

Follow this and additional works at: https://arrow.tudublin.ie/ehsiart

Part of the Educational Sociology Commons, Environmental Studies Commons, Medicine and Health Sciences Commons, Other Education Commons, and the Work, Economy and Organizations Commons

\section{Recommended Citation}

Verhoef, L.A., Bossert, M., Newman, J., Ferraz, F., Robinson, Z.P., Agarwala, Y., Wolff, P.J., Jiranek, P., \& Hellinga, C. (2019). Towards a Learning System for University Campuses as Living Labs for Sustainability. World Sustainability Series. DOI: 10.1007/978-3-030-15604-6_9

This Article is brought to you for free and open access by the ESHI Publications at ARROW@TU Dublin. It has been accepted for inclusion in Articles by an authorized administrator of ARROW@TU Dublin. For more information, please contact arrow.admin@tudublin.ie, aisling.coyne@tudublin.ie,gerard.connolly@tudublin.ie.

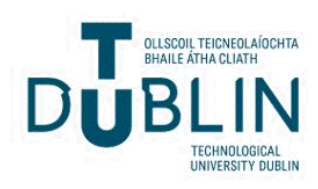




\section{Authors}

L.A. Verhoef, M. Bossert, J. Newman, Filipa Ferraz, Z.P. Robinson, Y. Agarwala, P. Wolff, P. Jiranek, and C. Hellinga

This article is available at ARROW@TU Dublin: https://arrow.tudublin.ie/ehsiart/23 


\title{
Towards a learning system for University Campuses as Living Labs for sustainability
}

\author{
L.A. Verhoef ${ }^{1}$, M. Bossert ${ }^{6}$, J. Newman ${ }^{2}$, F. Ferraz ${ }^{3}$, Z.P. Robinson ${ }^{5}$, Y. Agarwala ${ }^{1}$, P. Wolff $\mathrm{III}^{2}$, \\ P. Jiranek ${ }^{4}$, C. Hellinga ${ }^{1}$ \\ ${ }^{1}$ Delft University of Technology, ${ }^{2}$ Massachusetts Institute of Technology, ${ }^{3}$ Dublin institute of \\ Technology, ${ }^{4}$ ETH Zurich, ${ }^{5}$ Keele University,${ }^{6}$ Hochschule für Technik Stuttgart
}

Contact: Dr. Leendert Arie Verhoef, Sustainable Innovation Program Developer, Green Office/TU Delft. Email:1.a.verhoef@tudelft.nl

Keywords Living Labs, Co-creation, University Sustainability

\begin{abstract}
Universities, due to their sizeable estates and populations of staff and students, as well as their connections with, and impact within, their local and wider communities, have significant environmental, social and economic impacts. There is a strong movement for universities to become leaders in driving society towards a more sustainable future, through improving the sustainability of the built environment and the universities' practices and operations, and through their educational, research and wider community engagement missions. Around the globe the concept of 'Living Labs' has emerged as an instrument to integrate these different aspects to deliver sustainability improvements, through engaging multiple stakeholders in all of these areas, and through the co-creation of projects to improve the sustainability of the campus environment and operations, and to link these to the education, research, and wider community missions of the institution. This chapter describes a living, shared framework and methodology, the 'Campus as Living Lab' learning system, created through global participatory workshops and Living Lab literature, aimed at supporting universities and their Sustainability (Coordinating) Offices in the development and monitoring of Living Lab projects. The framework includes seven categories of supportive data collection and three levels of details to meet different requirements of potential users. The Living Lab framework presented in this chapter, aims to create value and help universities maximise the benefit of Living Lab projects within an institution, support monitoring, reflection and learning from projects, and facilitate communication with stakeholders, and the sharing of practices and learning between peers across the globe. As a living shared, framework and learning system, the framework will adapt and develop over time and within different contexts. To provide feedback and fast (practical) learning from users, the system will be further developed to facilitate transparent peer reviewing.
\end{abstract}

\section{Introduction}

There is increasing emphasis on the need for universities, or more generally institutions of higher education (HEI) around the world to play an increasingly important and critical role in society's movement towards a more sustainable future. HEIs as institutions with diverse missions and large estates are well placed to contribute to this agenda in unique ways, through: their education; their research; their wider community involvement, including business, government and community stakeholders; through their estate; and through the integration of all four of these areas. The substantial size of these institutions, often equivalent in area, population, and activities, to the size of a small (or not so small) town, as well as mostly part of a city system, 
creates an imperative to improve the sustainability of the estate and operations of the university campus.

Whilst the integration of the estate, education, research and wider community aspects within a HEI provide opportunities to use the campus to research and trial more sustainable solutions, and for the outcomes and processes of this research to be used in diverse ways to educate the HEI and wider community about sustainable solutions. The university campus and in some cases as well its neighbourhood therefore becomes a test bed, or 'living laboratory' (from now, 'Living Lab'), where solutions to increase the sustainability of the university estate and operations are researched and trialled, and integrated into education. The Campus as Living Lab framework seeks to leverage the maximum benefit to sustainable practice across all areas of a university's mission and operations.

The Living Lab approach aims to use research conducted within the university aimed at advancing sustainability principles across different levels of impact: the HEI's estate and operations; the educational curriculum; across the university and wider community; and society. To advance successfully the integration of sustainability principles across our campus operations and the built environment, we must have a deeper understanding of what works and what does not work. To successfully advance the integration of sustainability principles within the educational programmes and wider student (and staff) experience of the HEI, we must know what processes lead to desirable educational outcomes, and how best to integrate the research process and sustainable estate product most effectively into these areas. To bring forward the integration of sustainability principles within the wider communities of HEIs, we must understand how to communicate effectively with various stakeholders to boost a socio-ecological (sustainability) transition.

Questions that HEIs must tackle, to help advance sustainability principles in society include: How do we make informed decisions that lead to decreased environmental and human health impacts locally and globally? How do we plan for our campuses and cities to be resilient to a changing climate - today and in the future? How can our campuses and their neighbourhoods mitigate greenhouse gas emissions to the extent called for by the IPCC? These are the types of questions that warrant a shared framework to advance successful living labs on campuses, globally. Universities are now poised to leverage their unique ability to be a scalable laboratory in which to devise, pilot, implement and evaluate the best sustainable organisational to urban scale strategies of today and the emerging next-gen strategies for tomorrow (Newman, 2018).

The concept of an HEI as a Living Lab is relevant to HEIs all across the world. Yet the context in which HEIs exist both within and between countries varies significantly (den Heijer, 2011). For example, HEIs may be city based, with buildings distributed across a city; maybe campus based, with buildings housed within a single (or multiple) estate; they may be urban or rural. HEIs in different climatic environments across the world also face very different sustainability issues to address; for example, whether major energy costs are associated with heating or air conditioning. Governance structures for sustainability vary significantly between institutions, some have Sustainability (Coordination) Offices, some have more distributed sustainability responsibilities. Cultures within HEIs in different countries also differ, as do cultures between different HEIs in the same country. Within HEIs there are also diverse cultures of practice, between students, academic staff and faculty, professional services support staff, and estates operations staff. Cultures may even differ strongly within these groups for example between academic staff and faculty from different disciplines and fields. Alongside these diverse cultural contexts there can exist a problem of language, with diverse and contrasting terminology 
being used to describe the same phenomenon within different cultural contexts. It is therefore important that a globally useful framework is applicable and usable by people across these various cultural divides.

In this chapter the authors propose a framework and methodology for the development of Living Labs within HEIs; and present a shared living lab framework to achieve this, that will be open sourced and usable across a global divide. What distinguishes this approach from 'sustainability' research already taking place at our universities is the opportunity at one end to recognize and identify sustainability challenges at the campus to city scale that can catalyse applied research. On the back end, living lab models predominantly need to engage the user base, which leads to a quick feedback loop. Successful projects may therefore enable universities to advance sustainability more rapidly on their campuses. This alone warrants deeper research.

\section{Developing the Framework}

\subsection{A transformational process benefitting from existing ecosystems}

Fazey et al. (2018) state that "The most critical question for climate research is no longer about the problem, but about how to facilitate the transformative changes necessary to avoid catastrophic climate-induced change. Addressing this question, however, will require massive upscaling of research that can rapidly enhance learning about transformations." However, it is not just climate change, which society faces as a major issue relating to our environmental, social, and economic sustainability; and similar levels of research and transformations are needed across a much wider range of issues in our move towards a more sustainable future. Living Labs can be part of the solution to these problems of upscaling research and enabling transformation with many authors claiming that the most effective Living Labs are those making use of an actual existing environment with its own "ecosystem" of physical environment, structures, individuals, history, culture, weather, etc. - perfectly exemplified by the university campus.

Dealing with the necessary rate and scale of the required societal transformations for a more sustainable future, requires a transdisciplinary approach, integrating researchers and users (Baumgärtner et al., 2008; Boserup, 2010; Farley et al., 2010; Frame and Brown, 2008; Kajikawa, 2008; Kauffman, 2009; Komiyama and Takeuchi, 2006; Schneidewind, 2010; Steinfeld and Mino, 2009; Vandermeulen and Van Huylenbroeck, 2008; Weinstein, 2010). Jan et al. (2012) defines Transdisciplinarity as “... a critical and self-reflexive research approach that relates societal with scientific problems; it produces new knowledge by integrating different scientific and extra-scientific sights; its aim is to contribute to both societal and scientific progress; ...". For a Campus Living Lab this means that it should consider those critical and selfreflexive research approaches in order to conduct highly adaptive, reflexive, collaborative and impact-oriented research to enhance capacity to respond to the climate and other sustainability challenges (Fazey et al. 2018). It is these ideas, which underpin the development of the Living Lab learning system framework outlined in this chapter.

\subsection{Requirements for a valuable framework}

We have built this framework on a number of underlying assumptions of what our universities have in common and share across continents: People, organisational structures, place, costs, data and the desire to contribute to a more sustainable future, locally and globally. The Living Lab 
framework presented, that we call a 'Campus as Living Lab' learning system, aims to be useful in the following ways:

1. to support the planning stages of a campus-based sustainability project, to ensure that the educational, research and wider community benefits are maximised;

2. to support the monitoring of such projects, ensuring opportunities for benefits are fully explored throughout;

3. to support the reflection and internal learning of a project once completed, and ascertain ways to develop further impact;

4. as a tool to improve engagement with diverse stakeholders in the unique local environment. This methodology and framework is unique to the context of HEIs, because of their breadth of stakeholders through their combined education, research and wider community engagement missions as well as their extensive estate; and

5. as a way of disseminating good practice across the global sustainability HEI community, allowing people from across the world to easily access detailed case studies of processes, practices and products to inform their own work on sustainable practices in their own HEIs.

The framework is also focused specifically on using improvements in the sustainable practices of the campus environment and operations itself as the 'living lab', meaning that the HEI's community of staff and students comprises the various roles of the researchers and those being researched, as well as the educators and those being educated. However, this framework could also be modified for use in large organisations interested in improving their sustainability practices, educating their stakeholders, and learning and reflecting on the processes and impacts of changes in their practices. This framework could also be adapted within an HEI setting, where university researchers work within the local, or wider, community to improve sustainable practices external to the HEI, and use this research to feed into their own campus developments, and educational programmes and approaches. The localization and utilization of this framework is up to the practitioner on the ground to interpret, test, test again and apply, reflect, and rework until it is successful for their own context.

\subsection{A Co-creation process}

The framework integrates knowledge and experience of developing, and researching Living Labs within university campus environments. In developing the framework, the authors have studied literature about Living Labs (Gross, 2005; Liedtke et al., 2012; Brandt, 2013; König and Evans, 2013; Schneidewind, 2014; Trencher et al., 2014; Evans, 2015; Gross, 2015; Schäpke et al., 2015; Voytenko et al., 2015) literature about transition research and transformation science (Sharp, 2002; Cortese, 2003; Koester et al. 2006; Lozano, 2006; Ferrer-Balas et al. 2008; Pohl and Hadorn, 2008; Loorbach and Rotmans, 2010; Dunphy et al., 2014; ; Wagner and Grunwald, 2015) and reports created by organisations based on best practices and case studies (Lozano, 2006; Lang et al. 2012; Scholz and Steiner, 2015a; Scholz and Steiner, 2015b; Botero et al., 2017). An important element in the creation of this framework were the feed forward and feedback processes within the international HEI community.

The need for a framework such as the one presented was established in 2016, through the ISCN, the International Sustainable Campus Network - a global network aimed at supporting leading colleges, universities, and corporate campuses in the exchange of information, ideas, and best practices for achieving sustainable campus operations and integrating sustainability in 
research and teaching. For many years the ISCN has hosted a working group on 'Integrating Research, Teaching and Facilities', and in 2016 the group determined that a more methodological approach could be valuable to maximise the potential of this integrative approach. The co-authors from MIT, TUD, Keele, Hokkaido and ETH Zurich, entered into a process to develop a potential new framing for discussion in the ISCN Vancouver conference in 2017.

From the onset, it was decided not to make a framework and then to present it as a fixed 'take-it-or-leave-it' product, but rather to share the initial discussions for a framework and enter into a co-creation process, bringing in feedback and involvement of the ISCN participants. This approach was valued by the $30+$ participants, who agreed on the desirability of a framework and methodology, which integrated stakeholder involvement, provided support for the management of Living Labs, and enabled the connecting and sharing between peers. Based on these inputs, it was decided to move on, and attempt to build a more descriptive framework, with the help of more HEIs.

An initial framework was built using initial thinking (Verhoef et al., 2017) and the Vancouver working group report (Vancouver, 2017), taking the strengths from the various other Living Labs Methodologies, for example, AMS Institute (Steen et al., 2017), ENoLL (Malmberg, and Vaittinen, 2017 and Bodi et al., 2015), Keyson (Keyson, 2017), Social Labs, (Hassan, 2014), and Rathenau Institute (Maas, 2017). From these, the requirements for seven categories of data collection were extracted, referred to as: General, Scope, Participants \& Co-creators, Organisations, Outcomes, Impact, and Reflection \& Review. These are currently in the process of being further defined and parameterized. The Market Impact Assessment Methodology developed by New-Energy-Works for the European Commission was used to subdivide the impact category (Verhoef et al, 2004).

\section{Description of the framework}

\subsection{The seven data collection categories}

The proposed framework is meant to lead to the development of a database to collect key data about a Living Lab. It is designed to be a supportive instrument over the whole lifetime of a Living Lab - from initial planning stages, through monitoring phases, through to its final closure and reflection on the lessons learned. The seven categories for data collection cover all of the different stages of the Living Lab, and allow monitoring on whether outcomes and impacts set out in the initial stages have been met, and how partnerships, participants, co-creators and organisational structures have evolved. The seven data collection categories are:

1. General: a summary of the Living Lab location, key contacts, status, timelines and budget

2. Scope: the problem being addressed, historical details to the problem, the context, and the key sustainability 'theme' being addressed

3. Participants and Co-Creators: different stakeholders and ways in which they are engaged

4. Organisation: leading organisations, partnerships, potential risks

5. Outcomes: anticipated (and actual) sustainability outcomes in relation to the problem being addressed, as well as anticipated (and actual) educational, research and engagement outcomes

6. Impact: wider impacts outside of the Living Lab boundaries

7. Reflection and Review: evaluation of the Living Lab products and processes. 


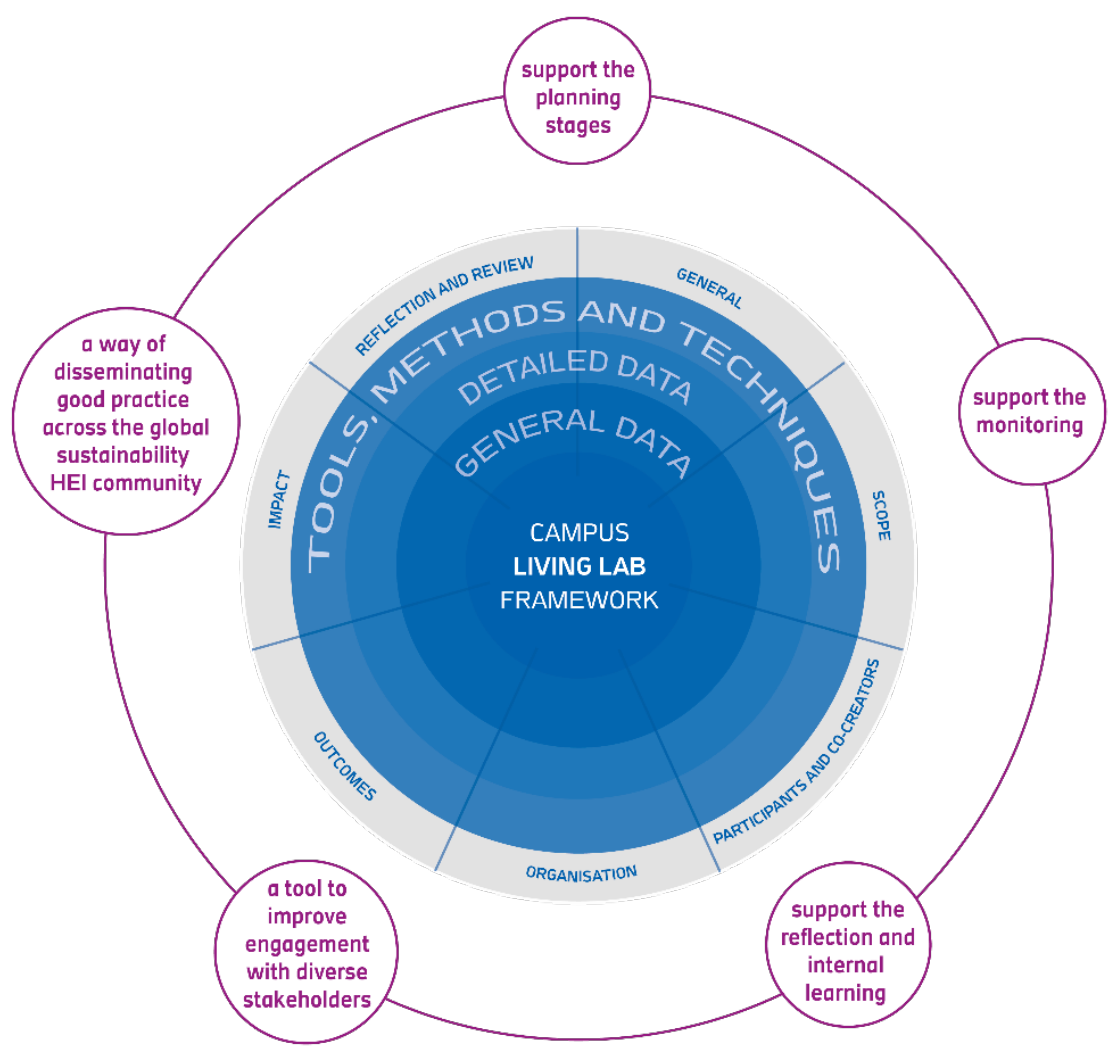

Figure 1. Campus as Living Lab Framework design with its seven categories and five potential values and three levels of detailing and application. Copyright the authors.

Through completing the data required in the planning stages of a Living Lab using this proposed framework, the user will gain guidance on the information needed to try and think through the different aspects to maximise the benefit of the Living Lab, and to enable learning from the Living Lab to be learnt from internally and shared externally.

The 'General' category contains contact information and data about the project management. The 'Scope' category guides the framework user through the key elements of the Living Lab. Inputs need to be precise and clear to all stakeholders who may be involved, clearly outlining the specific topic or problem being addressed by the Living Lab, the issues aiming to be addressed, or the area of innovation.

Category three, 'Participants and co-creators' requires the framework user to consider the necessary data about the methodology of the Living Lab, with specific consideration of the different stakeholders, therefore providing a clear picture of the outreach and the communication requirements of the Living Lab as well as the interaction complexity. This leads to category four 'Organisation', where the focus is on the organisational structure of the Living Lab.

The 'Outcomes' and 'Impact' categories allows the framework user to outline from the start the desired and predicted outcomes and wider impact of the project. With the increased visibility of the United Nation's Sustainable Development Goals (SDGs), and the move for many organisations to audit their activity against the SDGs, it may be desirable to link the 'Outcomes' and 'Impact' categories directly to the objectives of UN SDGs. For example, outcomes of Living 
Lab projects can refer to reduction in greenhouse gases, reduction of pollution to water bodies or the atmosphere, improved health, improved working conditions, and improved nutrition, which all have close relation to the SDGs. Outcomes can also refer to concrete physical changes in the University estate and its environment, changes in operations, processes or decision making, or educational outcomes for the campus community and society. The 'Impact' section depicts potential amplification avenues and effects, beyond the initial boundaries of the Living Lab.

These 'Outcomes' and 'Impacts' sections are also key in the monitoring phases of the project, to assist in monitoring how close the project is to the original anticipated outcomes and impact, and therefore any changes that may need to be put in place to ensure that the original desired outcomes are achieved. The insights, of this monitoring phase, and final reflections on the processes and products (outcomes and impacts) will be collected through category seven 'Reflection and Review'. This is the only part of the framework that is not completed as part of the initial planning stage, unless it is to be used to outline the documentation, or reflection processes, that are required to be collected throughout the Living Lab process, to feed into the final reflection process.

\begin{tabular}{|c|c|c|c|}
\hline General & Scope (Idea) & Participants \& Co-Creators & Organization \\
\hline $\begin{array}{l}\text { LEVEL } 1 \\
\text { Living Lab Information } \\
\text { Name .......... } \\
\text { Organisation ........... } \\
\text { City ........... } \\
\text { State ........... } \\
\text { Website ........... } \\
\text { Personal Information } \\
\text { (Projectmanager) } \\
\text { Name ........... } \\
\text { Email Address ........... } \\
\text { Phone ............ }\end{array}$ & $\begin{array}{l}\text { LEVEL 1 } \\
\text { Brief Description } \\
\text { Problems/Issues being addressed }\end{array}$ & $\begin{array}{l}\text { LEVEL } 1 \\
\text { Users Defined in advance? } \\
0 \text { yes } \\
\text { no } \\
\text { Type \& number of participants from University } \\
\text { Community } \\
0 \text { students } \\
\text { academic staff } \\
\text { non-academic staff } \\
\text { socio-political groups (eg.: members of } \\
\text { unions, members of campus,...) } \\
\quad \text { informal groups (eg.: all cyclists; etc.) } \\
\text { alumni }\end{array}$ & 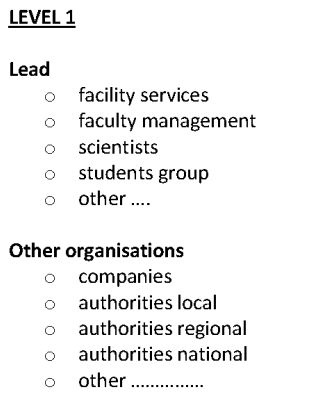 \\
\hline 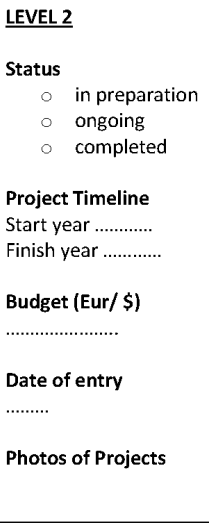 & $\begin{array}{l}\text { LEVEL 2 } \\
\text { Goal of innovation (total 100\%): } \\
\text { Education / learning ..................... } \\
\text { Research / Innovation ................. } \\
\text { University Sustainability ................\% } \\
\text { Living Lab Characteristics } \\
\text { Topic of the Living Lab } \\
\quad \text { Problems/ Issues being addressed } \\
\text { Participants/ Stakeholders } \\
\text { How are they addressed / description of } \\
\text { the way the joint Living Lab } \\
\text { communicates and defines research } \\
\text { questions, develops tasks, products, } \\
\text { services, processes etc. } \\
\text { Type of Living Lab (multi-, inter-, trans- } \\
\text { disciplinar) } \\
\text { How it developed, what was the initial } \\
\text { core point, who is the driving force and }\end{array}$ & 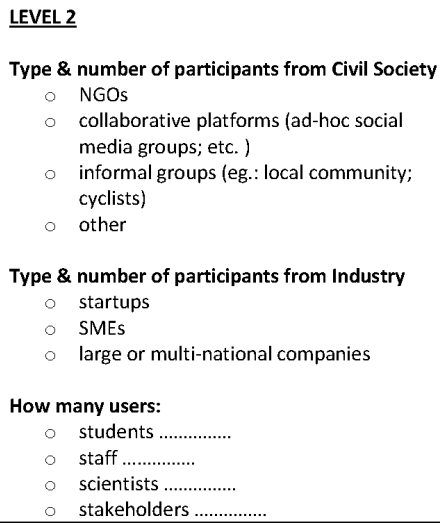 & $\begin{array}{l}\text { LEVEL } 2 \\
\text { Living Lab team leads } \\
\text { ofudents } \\
\text { studemic staff } \\
\text { non-academic staff } \\
\text { socio-political groups (eg.: } \\
\text { members of unions, } \\
\text { members of campus } \\
\text { committees; etc.) } \\
\text { informal groups (eg.: all } \\
\text { cyclists; etc.) } \\
\text { Organisation Layer } \\
\text { Bottom- Up (eg.: admin } \\
\text { staff, students, class etc.) } \\
\text { Middle-Out (eg.: operation } \\
\text { managers; chairs; etc.) } \\
\text { Top-Down (eg.: senior staff, } \\
\text { direction; board, etc.) } \\
\end{array}$ \\
\hline
\end{tabular}

Figure 2. Campus as Living Lab parameter list, work in progress, version 1.0, depicting the overall category and detailing for general, scope, user interaction and organisation. Copyright the authors.

\subsection{Three levels of detail and three stages of use}

The framework is designed to support the implementation and monitoring of an effective Living Lab learning system, through its seven categories of data collection. However, depending on the stage of the project or the user of the framework, they may choose to engage with the framework on three different levels, and at three different stages, the planning, monitoring, and review 
stages. These different levels and stages are still under development, but recognize the various different needs of different user groups, and how this might change throughout the lifetime of the project. An outline of the three different Levels at which users can engage is given below:

- Level 1: Overall data and basic information about the Living Lab. This assists in the initial description of the Living Lab, including outlining of the 'problem' being addressed and the anticipated broad outcomes and user groups. This Level relates to the early part of Stage 1, the Planning stage.

- Level 2: Detailed data. This refers to the collection of more precise information and parameters for the project, including specific outcome metrics, and anticipated numbers from different stakeholder groups. This Level encourages more detailed planning (Stage 1 - Planning), and also more detailed monitoring (Stage 2) and review (Stage 3), considering a greater range of questions and more detailed analysis.

- Level 3: The Living Lab 'toolbox'. This Level refers to guidance provided within the framework as to the tools, methods and techniques that can support the setting up, running, communicating, monitoring, and reviewing of a Campus Living Lab with various stakeholders from inside and outside the university community.

\subsection{Co-Development of the framework}

Testing the tool in several universities and collecting data from diverse Campus Living Lab projects has shown that the framework methodology can help guide and illuminate critical key points in the planning, monitoring and reflection stages of a Living Lab. However, the wording and naming of certain categories, headlines or participant and co-creator groups varies from country to country. Therefore, it is necessary to modify and improve the tool iteratively based on feedback loops of users from around the world, and working in different contexts, and to develop based on those findings a standard glossary for the definitions of words to facilitate wider use. Clearly in inputting data into the framework there is a balance to be had in terms of very minimalistic descriptions that may not provide enough detail to effectively inform people outside of the project, and very wordy descriptions which will reduce the likelihood that others will read through all of the information.

Users of the framework need to bear in mind the need for clarity and precision, and have in mind the need for the data inputted to be usable by a wide range of different stakeholders from many different cultural contexts. A shared framework and communication method will prevent too much space for different interpretations of Living Lab projects and make it possible to use the framework to publish project details on websites, databases, papers or press articles and to share learning between peers. Through the collection of these data and gathering them in an international platform it will be possible to search for universities or Living Labs dealing with similar issues and tasks, to use the framework as a source of learning between institutions as well as a starting point for conversations between institutions, enabling greater progress towards sustainable development in HEIs, and strengthening the ability of Living Labs to act as agents of change within their institutions and in society.

\section{Discussion}

\subsection{Living Labs strengthening university work towards UN SDGs}


The Campus as Living Lab learning system was created based on Living Lab literature, participatory workshops and expert discussion. The learning system has seven key categories for data collection (referred to as general, scope, organisation, participants and co-creators, outcomes, impact in the world and reflection and review).

The scope, outcomes and impact of Living Labs can relate closely to one or more of the UN SDGs. It should be noted that the UN SDGs are large-scale and long-term goals, where it is easy to think that single projects cannot visibly contribute. Yet small scale or incremental changes both contribute to the whole and can be scaled up to include more of an organisation, more organisations or similar projects in different organisations or contexts. This is particularly the case, as University campuses and their communities are significant in terms of urban and global built area and population, as well as in educating society's future leaders and global decision makers.

In 2015, there were 18,500 HEIs worldwide, with 212 million students and 13 million teachers (EdStats, 2018) and they are estimated to be responsible for $1.4 \%$ of global $\mathrm{CO}_{2}$ emissions (Verhoef, 2018). Therefore, universities have a responsibility to both reduce their negative impacts, improve their positive impacts, as well as educate everyone on and around the campus to be able to view the world through a sustainability lens, and be beacons of a move towards a more sustainable future.

\subsection{Creating value}

The Living Lab framework presented in this chapter, aims to create value to University's sustainability efforts in the following five ways:

1. to support the planning stages of campus-based sustainability projects, to ensure that the educational, research and wider community benefits are maximised;

2. to support the monitoring of such projects, ensuring opportunities for benefits are fully explored throughout;

3. to support the reflection and internal learning of a project once completed, and ascertain ways to develop further impact;

4. as a tool to improve engagement and communication with diverse stakeholders;

5. as a way of disseminating good practice across the global sustainability HEI community, allowing people from across the world to easily access detailed case studies of processes, practices and products to inform their own work on sustainable practices in their own HEIs.

Preliminary tests at the Delft University of Technology and the University of Applied Sciences Stuttgart show that the framework aids in highlighting issues covered, issues discarded and issues 'forgotten', and hence highlight the potential of the framework in delivering to both 1 and 2 of the 'uses' of the framework highlighted above. However, these preliminary tests also highlighted that many stakeholders are interested in the outcomes the framework delivers rather than the process. They value the idea that a trustworthy actor (e.g. the Sustainability Office) puts its knowledge, weight and confidence in the framework.

The fourth use of the framework above (engagement and communication with stakeholders) demonstrates how a more process-oriented approach can help in the implementation of a Living lab and in overcoming common barriers. The steps in starting that process are 1) recognising the envisioned (global) impact, 2) attaining common understanding of 
and respect for the various outcomes, 3) designing the work space with all stakeholders needs in mind (time, location, and resources). The elements for running an effective Living Lab require a holistic approach and effective connection and communication with all relevant users, researchers, educators and operations staff.

To ensure the fifth 'use' of this framework (peer-peer learning) requires the framework to include a feedback and fast (practical) learning system, preferably within existing practitioner networks within HEIs such as the ISCN. The system should facilitate open and non-anonymous peer reviewing. It is envisaged that the framework becomes a peer-reviewed system whereby case studies are entered and peer reviewed, and enter into an open access database.

\section{Conclusion and Next steps}

This paper describes a living, shared framework and methodology, the 'Campus as Living Lab' learning system, created through global participatory workshops and Living Lab literature, aimed at supporting universities and their Sustainability (Coordinating) Offices in the development and monitoring of Living Lab projects. The framework includes seven categories of supportive data collection, three levels of detail to meet different requirements of potential users, and three stages of use.

The Living Lab framework presented in this chapter, aims to create value and help universities maximise the benefit of Living Lab projects within an institution, support monitoring, reflection and learning from projects, and facilitate communication with stakeholders, and the sharing of practices and learning between peers across the globe. As a living shared, framework and learning system, the framework will adapt and develop over time and within different contexts. To provide feedback and fast (practical) learning from users, the system will be further developed to facilitate transparent peer reviewing.

Development of this framework has raised a number of questions with scope for further indepth and detailed investigations in relation to the design and operation of Living Labs. These key areas of questions may be categorized as follows:

- campus data acquisition; tracking and analysis and managing risk;

- educational and research outcomes;

- $\quad$ solution design, applicability, scalability and culture.

Within the area of campus data acquisition questions arise around how data is collected and managed - how do we handle the real and perceived risks that come with greater transparency? How do we handle privacy issues that may exist in the accessibility of data sets? Can increasing data access, enhance transparency, and through enhanced transparency impact behaviours and decisions to ensure maximum sustainability benefits?

In the area of educational and research outcomes questions arise about how to use campus-based sustainability projects to maximise educational outcomes, for example how can we make 'invisible' sustainability improvements 'visible' and a source of learning for both the student and staff population, through what is referred to as the 'hidden' or 'subliminal' curriculum (Winter and Cotton 2012; Robinson and Madley, 2017), and how do we engage the breadth of the research community?

Finally, in the area of solution design, applicability, scalability and culture, questions arise in how we encourage the replication and upscaling of the process, ensuring a culture which values incremental advances, and the replication of process, so that we are not all driven to 
design our own version of the wheel. Our framework can be seen as yet another approach. However, through its incremental, participatory and on-going development, we hope that this framework can be something that the global university community can own, develop, and apply within their own contexts to maximise the benefits to all stakeholders, as well as being used to share the stories of Living Labs and related scholarship in ways that make the research more accessible and in turn applicable, and ultimately help universities drive genuine and lasting change towards a more sustainable future.

\section{References}

Baumgärtner, S., Becker, C., Frank, K., et al. (2008). Relating the philosophy and practice of ecological economics: the role of concepts, models, and case studies in inter and transdisciplinary sustainability research. Ecological Economics 67 (3), 384-393.

Boserup, E. (2010). An interdisciplinary visionary relevant for sustainability. PNAS 107 (51), $21963-21965$.

Botero L., Bossert M., Eicker U., Cremers J., Palla N., Schoch C. (2017). A Real-World Lab Approach to the Carbon Neutral Campus Transition: A Case Study. In: Leal Filho W., Mifsud M., Shiel C., Pretorius R. (eds) Handbook of Theory and Practice of Sustainable Development in Higher Education. World Sustainability Series. Springer, ChamCortese, Anthony D. (2003). The critical role of higher education in creating a sustainable future. Planning for Higher Education, 31 (3), 15-22.

Brandt, P., Ernst, A., Gralla, F., Luederitz, C., Lang, D., Newig, J., et al. (2013). A review of transdisciplinary research in sustainability science. Ecological Economics, 92, 1-15.

Bódi Z., et al. (Eds.), Living Lab services for Business support and Internationalisation, ENoLL, 2015

Cortese, Anthony D. (2003). The critical role of higher education in creating a sustainable future. Planning for Higher Education, 31 (3), 15-22.

den Heijer A. (2011). Managing the University Campus. Eburon Academic Publishers, Delft, ISBN 978-90-5972-487-7 (paperback); 978-90-5972-488-4 (eBook)

Disterheft A., Caeiro S., Azeiteiro U.M., Leal Filho W. (2013). Sustainability Science and Education for Sustainable Development in Universities: A Way for Transition. Caeiro S., Filho W., Jabbour C., Azeiteiro U. (eds) Sustainability Assessment Tools in Higher Education Institutions. Springer, Cham

Dunphy, Dexter C., Benn, S., Griffiths, A. (2014). Organizational change for corporate sustainability. Abingdon, Oxon: Routledge.

EdStats (2018). Worldbank / UNESCO Institute for Statistics, retrieved 19 march 2018

Evans, J., Jones, R., Karvonen, A., Millard, L., Wendler, J. (2015). Living labs and coproduction. University campuses as platforms for sustainability science. Current Opinion in Environmental Sustainability 16, 1-6. DOI: 10.1016/j.cosust.2015.06.005

Farley, J., Batker, D., de la Torre, I., Hudspeth, T. (2010). Conserving mangrove ecosystems in the Philippines: transcending disciplinary and institutional borders. Environmental Management 45, 39-51.

Ferrer Balas, D.; Adachi, J.; Banas, S.; Davidson, C. I.; Hoshikoshi, A.; Mishra, A. et al. (2008). An international comparative analysis of sustainability transformation across seven universities. International Journal of Sustainability in Higher Education 9 (3), 295-316. DOI: $10.1108 / 14676370810885907$. 
Gross, M., Hoffmann-Riem, H., Krohn, W. (2005). Realexperimente - Ökologische Gestaltungsprozesse in der Wissensgesellschaft. Transcript Verlag, Bielefeld

Gross, M. (2015). Give Me an Experiment and I Will Raise a Laboratory. Science, Technology, \& Human Value 2015, 1-22.

Hassan, Z. (2014). The Social Labs Revolution. Berett-Koehler Publishers, ISBN 978-1-62656073-4.

Fazey, I., Schäpke, N., Caniglia, G., Patterson, J., Hultman, J., van Mierlo, B., Säwe, F., Wiek, A., Wittmayer, J., Aldunce, P., Al Waer, H., Battacharya, N., Bradbury, H., Carmen, E., Colvin, J., Cvitanovic, C., D’Souza, M., Gopel, M., Goldstein, B., Hämäläinen, T., Harper, G., Henfry, T., Hodgson, A., Howden, M. S., Kerr, A., Klaes, M., Lyon, C., Midgley, G., Moser, S., Mukherjee, N., Müller, K., O’Brien, K., O’Connell, D.A., Olsson, P., Page, G., Reed, M.S., Searle, B., Silvestri, G., Spaiser, V., Strasser, T., Tschakert, P., Uribe-Calvo, N., Waddell, S., Rao-Williams, J., Wise, R., Wolstenholme, R., Woods, M., Wyborn, C. (2018). Ten essentials for action-oriented and second order energy transitions, transformations and climate change research, Energy Research \& Social Science, Volume 40 (2018), 54-70, ISSN 2214-6296, https://doi.org/10.1016/j.erss.2017.11.026.

Frame, B., Brown, J. (2008). Developing post-normal technologies for sustainability. Ecological Economics 65 (2), 225-241.

Kajikawa, Y. (2008). Research core and framework of sustainability science. Sustainability Science 3, 215-239.

Kauffman, J. (2009). Advancing sustainability science: report on the International Conference on Sustainability Science (ICSS) 2009. Sustainability Science 4, 233-242.

Keyson D.V., Guerra-Santin, O. (2017). (Eds), Living Labs, Design and Assessment of Sustainable Living, Springer, ISBN 978-3-319-33526-1, ISBN 978-3-319-33527-8 (eBook)

Koester, R. J., Eflin, J., Vann, J. (2006). Greening of the campus. A whole-systems approach. Journal of Cleaner Production 14 (9-11), 769-779. DOI: 10.1016/j.jclepro.2005.11.055.

König, A., Evans, J. (2013). Experimenting for sustainable development? Living laboratories, social learning, and the role of the university. In König, A. (ed.) Regenerative sustainable development of universities and cities: the role of living laboratories. Cheltenham: Edward Elgar, 2013. p. 1-24.

Komiyama, H., Takeuchi, K. (2006). Sustainability science: building a new discipline. Sustainability Science 1, 1-6.

Lang, D., Wiek, A., Bergmann, M., Stauffacher, M., Martens, P., Moll, P., et al. (2012), Transdisciplinary research in sustainability science: Practice, principles, and challenges. Sustainability Science, 7(1), 25-43.

Loorbach, D., Rotmans, J. (2010). The practice of transition management: Examples and lessons from four distinct cases. Futures, 42, 237-246.

Liedtke, C., Welfens, M., J., Rohn, H., Nordmann, J. (2012). Living Lab: user-driven innovation for sustainability. International Journal of Sustainability in Higher Education, 13(2), 106 118.

Lozano, R. (2006). Incorporation and institutionalization of SD into universities. Breaking through barriers to change. Journal of Cleaner Production 14 (9-11), 787-796. DOI: 10.1016/j.jclepro.2005.12.010.

Lozano, R. (2006). A tool for a graphical assessment of sustainability in universities. Journal of Cleaner Production, 14 (9-11), 963-972. 
Maas, T., van den Broek, J., Deuten, J. (2017). Living labs in Nederland - Van open testfaciliteit tot levend lab, Den Haag, Rathenau Instituut

Malmberg, K. and Vaittinen, I. (Eds.), Living Lab Methodology Handbook, ENoLL, 2017

Newman, Julie (2018). Calling for a Next-Generation Sustainability Framework at MIT. Studies in Systems, Decision and Control: Sustainable Interdependent Networks. Vol. 145, Springer, pp. 13-20.

Pohl, C., Hadorn, G., H. (2008). Core Terms in Transdisciplinary Research. Hadorn G.H. et al. (eds) Handbook of Transdisciplinary Research. Springer, Dordrecht

Robinson, Z.P., Madley, I. (2017). Creating a campus-scale laboratory for low carbon energy research. Environmental Scientist, 26(4), 40-45.

Schäpke, N., Singer-Brodowski, M., Stelzer, F., Bergmann, M., Lang, D. J. (2015). Creating Space for Change: Real-world Laboratories for Sustainability Transformations: The Case of Baden-Württemberg. GAIA 24/4, 281- 283.

Schneidewind, U. (2010). An institutional reform agenda for the establishment of transdisciplinary sustainability research. Gaia 19 (2), 122-128.

Schneidewind, U. (2014). Urbane Reallabore - ein Blick in die aktuelle Forschungswerkstatt. pnd $\mid$ online III, 1-7.

Scholz, R., Steiner, G. (2015a). The real type and ideal type of transdisciplinary process: Part Itheoretical foundations. Sustainability Science, 10, 527-244.

Scholz, R., Steiner, G. (2015b). The real type and ideal type of transdisciplinary process: Part IItheoretical foundations. Sustainability Science, 10, 653-671.

Sharp, L. (2002). Green campuses. The road from little victories to systemic transformation. International Journal of Sustainability in Higher Education 3 (2), 28-145. DOI: 10.1108/14676370210422357.

Steen, K.Y.G., Van Bueren, E.M., (2017). Urban Living Labs: A Living Lab Way of Working AMS Research report, AMS Institute

Steinfeld, J.I., Mino, T. (2009). Education for sustainable development: the challenge of transdisciplinarity. Sustainability Science 4, 1-2.

Trencher, G., Bai, X., Evans, J., McCormick, K., \& Yarime, M. (2014). University partnerships for co designing and co-producing urban sustainability. Global Environmental Change, 28, $153-165$.

Vancouver, (2017). Report workshop Campus as Living Labs, 2017

Vandermeulen, V., Van Huylenbroeck, G. (2008). Designing trans-disciplinary research to support policy formulation for sustainable agricultural development. Ecological Economics 67 (3), 352-361.

Verhoef, L.A., Dingenouts, M.W.L., Schorel, J. (2004). Market Impact Assessment of Altener Projects, EC contract no. 4.1030/T/02-002, 2004.

Verhoef, L.A, Graamans, L., Gioutsos, D, van Wijk, A.J.M., Geraedts, J., and Hellinga, C. (2017). ShowHow: A flexible, structured approach to commit university stakeholders to sustainable development, Handbook of Theory and Practice of Sustainable Development in Higher Education (Volume 6), eds. Walter Leal Filho, 2017, Springer, pp 491-508

Verhoef, 2018, De Campus als Living Lab voor de Circulaire Economie, Nederland Circulair in 2050, ed. P. Luscuere, 208, in preparation

Voytenko, Y., McCormick, K., Evans, J., \& Schliwa, G. (2015). Urban living labs for sustainability and low carbon cities in Europe: Toward a research agenda. Journal of cleaner Production, 1-10. 
In: Universities as Living Labs for Sustainable Development: Supporting the Implementation of the Sustainable Development Goals - Volume 2. Springer, ed. Leal, W. et al., 2018 (in press)

Wagner, F., \& Grunwald, A. (2015). Reallabor als Forschungs-und Transformationsinstrument. Die Quadratur des hermeneutischen Zirkels. GAIA, 24(1), 26-31.

Weinstein, M. (2010). Sustainability science: the emerging paradigm and the ecology of cities. Sustainability: Science, Practice, \& Policy 6 (1), 1-5.

Winter, J. and Cotton, D. (2012). Making the hidden curriculum visible: sustainability literacy in higher education. Environmental Education Research, 18(6), 783-796. 